International Journal of Linguistics, Literature and Translation

ISSN: 2617-0299 (Online); ISSN: 2708-0099 (Print)

DOI: 10.32996/ijltt

Journal Homepage: www.al-kindipublisher.com/index.php/ijltt

\title{
The Proclaimer: An Emerging Medium for Literacy Promotion and Language Revitalization in Cameroon
}

\author{
James N. Tasah 8 (D) \\ Faculty of Arts, Letters and Social Sciences, University of Maroua, Cameroon \\ $\triangle$ Corresponding Author: James N. Tasah, E-mail: jtasah@yahoo.com
}

ARTICLE INFORMATION

Received: July 08, 2021

Accepted: August 10, 2021

Volume: 4

Issue: 8

DOI: $10.32996 / i j l l t .2021 .4 .8 .3 .16$

\section{KEYWORDS}

Proclaimer, Audio Scripture, Illiteracy, Listening, Revitalization

\section{ABSTRACT}

Community response to the publication and effective reading of the translated New Testament (NT) into Vernacular New Testament (Henceforth VNT) in different languages in particular, and literacy development in general was not sufficient enough before the inception of Audio Scriptures in Cameroon. One of the obstacles to the reading of the VNT among other literacy materials in local languages is illiteracy. This paper explores the use of Proclaimers (Audio Scriptures) in Bafut, Kom, Kako and Ngiemboon communities. It argues that their use is crucial in the generation of interest in literacy development and the revitalization of the target languages. Data for the study was obtained through quantitative and qualitative approaches. The findings revealed that the effective use of Audio Scriptures enhances the reading of the translated VNT and arouse interest in literacy promotion and the revitalization of the languages under study. The findings are in line with the 20th-century realities of the social media, where there is a growing use of Scriptural and other relevant indigenous information on audio and video formats for effective dissemination and comprehension.

\section{Introduction}

The greatest driving force behind the exponential growth of Christianity in Sub-Saharan Africa in the twentieth century was the translation of the Bible into vernacular languages (Sanneh, 1989; Bediako, 1995; Draper, 2006:181). The reception of the Bible in Vernacular languages strongly stimulated the cultural awareness of African peoples. That their own cultures were capable of receiving the written Word of God, revitalized their cultural self-esteem, and that in a time of Western colonialism (Maluleke, 2000:102). Even though much time and effort are expended in the translation of the New Testament (NT) Bible from imported colonial languages into different minority languages over the years (ten to fifteen) in Cameroon, only a paucity of the indigenous population usually succeeds in using the Vernacular New Testament (Henceforth VNT) Bible. Virtually all normal human beings can hear and speak, but very few in comparison can read and even less actually write, particularly in their Mother Tongues (MT). This state of affairs deserves serious attention in this era of globalization where increasingly, illiterate people may have to operate in situations where reading, writing, and counting are unavoidable.

Literacy activities, as stated above, have been enthusiastically promoted in Cameroon by some Non-Governmental Organizations (NGOs) such as the Summer Institute of Linguistics (SIL), Cameroon Association for Bible Translation and Literacy (CABTAL) and the National Association of Cameroon Language Committees (NACALCO) but since the response from the target communities was insufficient, they were not sustainable. Thus, any literacy program that is not self-sustaining may eventually stagnate when the enthusiasm or motivation dies down and there is no continued use of skills. Two opposing forces are noted: the need for continuous training and support by maintaining the status quo, and the introduction of a new approach through the use of Audio Scriptures to reinforce reading skills in these communities that are largely oral.

\section{K C AL-KINDI CENTER R D FOR RESEARCH AND DEVELOPMENT} Your gateway to world-class research

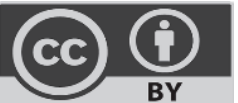

Published by Al-Kindi Center for Research and Development, London, United Kingdom. Copyright (c) the author(s). This open access article is distributed under a Creative Commons Attribution (CC-BY) 4.0 license 
Oral communication generally dominates the daily life of most communities in Cameroon. Since communication is almost always in the community's local language, it was only natural for the members of the communities under study to spontaneously embrace Proclaimers, given that they were listening to them in their respective languages orally. Although literacy is slowly gaining ground in these communities through the use of this device, the large majority of the population may still remain illiterate and thereby be exposed to all forms of exploitation. Tadadjeu (2004) states that illiterate adults who are cut off from national development and exploited by new socio-economic systems speak African languages. These adults have an important socio-cultural message for the new generation. They know the traditional social system from which the new ones should develop and the local value system. They possess the traditional scientific and technological heritage that helped the communities live through centuries. In this respect, vital traditional information from some illiterates will continue to be transmitted orally from one generation to another for the linguistic and cultural development of these languages.

In fact, audio-visual productions generally depend on a 'script'. That is, a very controlled and detailed way of ensuring no changes are made during the production process. There are, of course, good reasons for this. In the case of Proclaimers or Scripture Apps, they were vital and the original texts were written down by trained translators and checked by a translation consultant, and that all recordings perfectly matched the original text.

The production of Audio Scriptures is somehow an alternative for the encouragement of reading and writing skills. It is one of the important strategies to address illiteracy in a more culturally adaptable way in largely oral communities. Thus, introducing reading and writing skills in a massively illiterate population is like mixing both water and oil. With much agitation and activity, the oil will spread throughout the water but the oil does not penetrate the water. When the agitation stops, the oil will separate from the water. Put differently, if the impetus for a change in literacy touches only the surface of the community, the change does not continue after the impetus is exhausted, but when there is only a surge of enthusiasm, nothing permanent remains when the interest ceases or dies. The Proclaimer is like an agent and catalyst that is being used to break down 'oil' and 'water' as two opposing forces to literacy promotion in the target communities in particular and Cameroon in general. If it is considered a catalyst in enhancing literacy activities, then it is important to provide a definition of this gadget. This study aims to explore the use of Proclaimers as emerging literacy development and language revitalization tool in the target communities.

\subsection{The Proclaimer}

A Proclaimer (See figure1 below) is a digital player dedicated to playing Scriptures in a local language. It was developed primarily as a playback device for poor and illiterate people who may not have any other source to hear the Scriptures. It is a self-powered audio player that is designed to be used in remote and rugged locations. Its embedded microchip is pre-loaded with the NT in local languages. The sound recording of the Proclaimer is built into a device that looks similar to a cassette player. The device is powered by solar energy, batteries or electricity. It requires no maintenance and is virtually indestructible because it has no moving parts. According to Margetts (2019), Proclaimer is designed to contain the Scripture recordings made by Faith Comes By Hearing (Henceforth FCBH) or by its partners. It is in active use in many thousands of listening group programmes around the world. As such, the Proclaimer has fixed content (usually the whole NT) that cannot be removed or changed. One cannot use these players to contain self-recorded audio material. A team of specialists leads the whole recording and editing process. Although a language team might feel they could do it themselves, they are likely to underestimate the time required for them to do such recording and editing amid all their other responsibilities.

\subsection{Brief History of the Proclaimer}

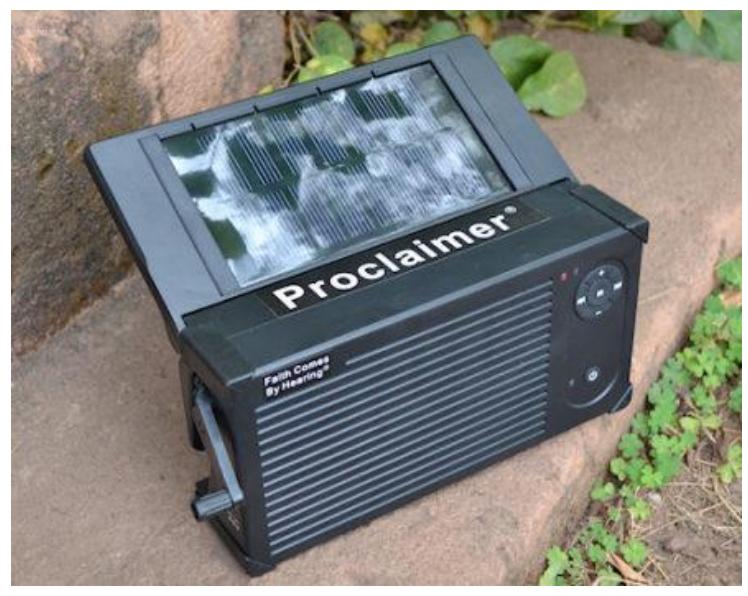

Fig 1. Proclaimer: an audio-bible Sources: Our Field Survey, 2021

According to Soggard (1995), the Hosanna Ministry started in 1972 by a missionary couple on a Hopi reservation. They discovered a sizable slash of Hopi Bibles but they realized that the treasure was of little use, as the tribe was mostly illiterate. In the course of that time, they discovered the power of providing the Scriptures in an audio form. The Bible, they realized, was a closed book to those who cannot read and had minimal impact on oral cultures. They soon had a vision to share God's word in an audio format to the world. This was based on their understanding that listening to Scriptures in one's 'heart language' enables the listener(s) to make a deep connection with it. As a result, they began an audiotape lending library in 1972. The Ministry soon streamlined its focus on providing audio Bibles through churches. This was motivated by their 
desire to provide the Scriptures to poor and illiterate people in a culturally relevant format with their observation that two thirds of the world's population was oral communicators, the need to share Scriptures with the oral majority became apparent.

Today, the Hosanna Ministry FCBH partners with more than 145 Bible Ministries to get Scriptures to every ethnic, language, people and nation. Thus, a national FCBH team travels to the region to record the NT as soon as the translation is completed. The recording team, native speakers and music and sound effects combine to create an Audio Drama Bible. Currently, 525 languages have already completed the programme. FCBH Ministry is the largest producer and distributor of audio Bibles worldwide. For over three decades, the Ministry has continued to grow and expand. One of its goals was to record and distribute Audio Bibles in 2000 languages and to start 2 million listening groups by 2016.

The Ministry recorded their first Bible on Cassette in 1973 and a few years later, they recorded the complete NT in 66 languages and since then, more languages have been recorded. Soggard indicates that the first project was recorded in 1985 and during these last 10 years, the international director's relentless drive, global vision and enthusiasm is to help in establishing FCBH programme in some 35 countries around the world.

In the late 1980s, FCBH was approached by Wycliffe translators, who found that the majority of the people were unable to read what they had worked so hard to translate. They realized that the Audio Bible could bridge that gap. Since then FCBH and Wycliffe have joined together in more than 90 recording projects, with another 90 projects in process.

Information from Wycliffe (2009) indicates that FCBH takes the finished product of the completed translations of the NT done by Wycliffe personnel and produces a high-quality, dramatized, and word-for-word audio recording. It describes the Proclaimer as a digital device that replaces audiocassettes and players. Wycliffe Bible Translators' goal is to create access to the Scriptures. Their intention to see the translated Scriptures used particularly by the illiterates is because, according to Wycliffe, listening is a powerful way to put God's living, active word into the hearts and minds of people. They also maintain that access is in audio format for millions of people, and thanks to their partnership with Hosanna Ministries, FCBH, the Scriptures are reaching the hearts of people where they have completed the translation of the NT into a local language.

\section{Methodology}

\subsection{Participant observation}

Participant observation was informally used in the collection of data related not only to Audio Scripture use but also to churchbased and adult literacy classes. This approach was particularly relevant by virtue of the fact that it enabled the researcher to collect some information that questionnaires could not accurately provide. Some of the stakeholders that provided more useful information in the course of participant observation were the facilitators, literacy monitors, listeners of the Proclaimer, among others.

\subsection{Direct interviews}

Interviews were also used to elicit a wide range of testimonies on the use of the Proclaimer in the selected communities. The main objective of interviews was to obtain information about the usefulness of the audio device in the literacy development of the target communities. Interviews were conducted generally with some of the target community members such as promoters, monitors, language community members, and some of those involved in the listening of Audio Scriptures.

\subsection{The Questionnaires}

Questionnaires were designed to find out the impact of the programme on the respondents' literacy development. Some of the participants who could not read English or French were assisted in filling in the questionnaires by literacy monitors in the respective MTs.

\subsection{Administration of questionnaires}

A questionnaire was carefully designed to elicit issues related to the use of Proclaimer and its impact on participants. They were administered essentially to a sample of 303 members of the listening groups and students in adult literacy classes in the target communities as well as the programme coordinators in Bafut, Kom, Kako and Ngiemboon

\subsection{Scope of the study}

This study is limited to a sample population drawn from Bafut, Kom, Kako, and Ngiemboon in Cameroon. It adopts a descriptive survey research design. This is considered appropriate for the work since it is concerned with an exploration of the Proclaimer as an emerging medium for literacy development and revitalization of the languages under study. 


\subsection{Sampling}

It is a way of selecting a given number of informants from a defined population to represent that population or community. Stratified random sampling was used to select the research informants from the four language communities. This was done in order to draw a representative sample from the number of informants targeted from children to the old.

\subsubsection{Distribution of Respondents according to age groups}

The participants who participated in the listening programme comprise children, youths, and the old. Given that the listening meetings were programmed in the different quarters where the participants were living as well as in churches, different categories of people were present in most of the sessions. The following table represents the different categories of the sample population distributed following the different age groups.

Table 1: Distribution of respondents according to age groups

\begin{tabular}{|l|l|l|l|l|l|l|l|l|}
\hline Age group & \multicolumn{2}{l}{$\mathbf{8 - 1 2}$ years } & \multicolumn{2}{l|}{$\mathbf{1 3}$ years } & \multicolumn{2}{l|}{$\mathbf{2 0 - 4 9}$ years } & \multicolumn{2}{l|}{$\mathbf{5 0 - 7 0}$ years } \\
\hline Village & count & percent & count & percent & count & percent & count & percent \\
\hline Bafut & 23 & $31 \%$ & 27 & $36.5 \%$ & 14 & $19 \%$ & 10 & $13.5 \%$ \\
\hline Kom & 21 & $28 \%$ & 27 & $36 \%$ & 12 & $16 \%$ & 15 & $20 \%$ \\
\hline Kako & 10 & $13.3 \%$ & 18 & $24 \%$ & 27 & $36 \%$ & 20 & $26.7 \%$ \\
\hline Ngiemboon & 16 & $20.3 \%$ & 14 & $17.7 \%$ & 38 & $48.1 \%$ & 11 & $13.9 \%$ \\
\hline Total & 70 & $23.1 \%$ & 86 & $28.4 \%$ & 91 & $30 \%$ & 56 & $18.5 \%$ \\
\hline
\end{tabular}

This table shows that the sample was not evenly distributed among the various age categories. The population sampled for analysis were conflated by generation with the children between the ages of $8-12$ years comprising 70 (23.1\%) of the sample, while teenagers (13-19 years) constituted of $86(28.4 \%)$ of the respondents. Adult respondents who fell within the age bracket 20-49 years constituted 91 (30\%) of the sample while the old who fell within the age bracket 50-70 years constituted 56 (18.5\%).

\section{Data Analysis}

The study employed descriptive statistical methods. This implies that the simple percentages and frequency tables were used for descriptive inferences. However, before looking at the emergence of literacy promotion as a result of Proclaimers, it is necessary to provide statistics relating to the number of Proclaimers received, annual listeners and the number of groups formed from the inception of the programme (2008 to 2010) in the four communities.

Table 2: Distribution of languages and Proclaimers and the No. of groups formed from 2008 to 2010

\begin{tabular}{|c|c|c|c|c|c|c|c|c|}
\hline \multirow{2}{*}{$\begin{array}{c}\text { Years } \\
\text { /Langua } \\
\text { ge } \\
\end{array}$} & \multicolumn{2}{|c|}{ Bafut } & \multicolumn{2}{|c|}{ Kom } & \multicolumn{2}{|c|}{ Kako } & \multicolumn{2}{|c|}{ Ngiemboon } \\
\hline & $\begin{array}{c}\text { No of } \\
\text { Proclaimers } \\
\text { received } \\
\end{array}$ & $\begin{array}{l}\text { No of } \\
\text { groups } \\
\text { formed }\end{array}$ & $\begin{array}{c}\text { No of } \\
\text { Proclaimers } \\
\text { received }\end{array}$ & $\begin{array}{l}\text { No of } \\
\text { groups } \\
\text { formed }\end{array}$ & $\begin{array}{c}\text { No of } \\
\text { Proclaimers } \\
\text { received } \\
\end{array}$ & $\begin{array}{c}\text { No of } \\
\text { groups } \\
\text { formed }\end{array}$ & $\begin{array}{c}\text { No of } \\
\text { Proclaimers } \\
\text { received } \\
\end{array}$ & $\begin{array}{l}\text { No of } \\
\text { groups } \\
\text { formed }\end{array}$ \\
\hline 2008 & 110 & 125 & 100 & 50 & 100 & 100 & 100 & 143 \\
\hline 2009 & 50 & & 59 & & 55 & & 43 & \\
\hline \multirow[t]{2}{*}{2010} & 20 & 175 & 20 & 235 & 50 & 55 & 50 & 132 \\
\hline & & & & & 50 & & 50 & \\
\hline TOTAL & 460 & 442 & 451 & 469 & 542 & 242 & 494 & 528 \\
\hline
\end{tabular}

The table above shows that Kako received the highest number of Proclaimers, followed by Ngiemboon while Bafut received 460 and Kom received 451 Proclaimers. In terms of the number of groups formed in the respective communities, Ngiemboon had the highest total number of groups while Kako recorded the least number of groups. While Kom speakers were the second in the formation of listening groups, Bafut was the third. An analysis of the total number of Proclaimers received by the respective communities and the total number of groups formed between 2008 to 2010 revealed that there is no correlation between the total number of Proclaimers received and the number of listening groups formed in the target communities. Statistics were only obtained on the annual number of 
listening groups formed in the four communities and the total number of listening groups from 2008 to 2010 as shown in the table below.

Table 3: Distribution of languages in terms of number of listening groups

\begin{tabular}{|l|l|l|l|l|}
\hline \multicolumn{1}{|c|}{ Languages } & \multicolumn{3}{c|}{ Total No. of Listening Groups } & Total No. of Listeners \\
\hline Years & $\mathbf{2 0 0 8}$ & $\mathbf{2 0 0 9}$ & $\mathbf{2 0 1 0}$ & \\
\hline Bafut & 13.000 & 12.375 & 15.700 & 41.075 \\
\hline Kom & 3.165 & 10.487 & 14.646 & 28.298 \\
\hline Kako & 2.114 & 13.041 & 12.662 & 27.817 \\
\hline Ngiemboon & 3.011 & 17.723 & 24.937 & 45.0671 \\
\hline
\end{tabular}

This table presents the total number of listening groups annually for the respective languages from 2008 to 2010 . An analysis of the groups revealed that Ngiemboon had the highest number of listening groups and highest number of listeners followed by Bafut while Kom and Kako shared the third and fourth positions respectively. As pointed out above, the level of participation of the speakers in the programme was not a function of the number of Proclaimers received. This view is pertinent because Kako facilitators received the highest number of Proclaimers but had the least number of listening groups and listeners. However, this was probably due to a combination of other factors since Ngiemboon which also received more Proclaimers than Bafut and Kom, also had more groups and listeners than Bafut and Kom. In the following section, the impact of literacy in the selected communities will be assessed from the perspective of community response.

\subsection{Community Response to Literacy}

According to Tasah (2012) the response of the respective participants to literacy through the use of this audio device was roundly positive given that in the target communities, churches were at the forefront. In fact, the different Christian churches, such as Catholic, Presbyterian, and Baptist, were increasingly becoming sites of MT literacy acquisition. When the promoters trained in the four communities started the programme, participants' reactions to non-Christians and particularly Christians were overwhelming. From our observation, all categories of the participants were greatly enraptured in the course of the listening sessions. As some participants were completely engrossed while listening to the audio Scriptures, their hearts seemed to move as they came to the awesome realization that the great God also speaks and understands their language. Since God speaks to them through the medium of the Proclaimer; this brought joy, hope, awakened faith in the listeners, and generated their interest in literacy.

In addition, the positive response of most of the participants from the selected communities on the basis of our observation revealed that there was a heightened sense of self-esteem, justified pride in their languages both in the course of listening sessions and even after such programmes. This can also be justified following information from some of the promoters that some churches decided to contribute money monthly to pay the transport fare for some of the promoters to enable them to reach out with the Proclaimers to other churches and groups mostly in the outskirts after the official financial assistance from SIL ended. If the speakers from different churches could contribute money for the promotion of the programme, it demonstrates community's acceptance and readiness to promote not only Scripture use but also literacy development in their communities. On the basis of the above, the Proclaimer can be considered as a shining example of community response to literacy. Globally, the participants' response from this perspective can be considered positive as many are increasingly attached to their languages through the programme.

From our observation, participants' desire for literacy was generated in the course of listening activities, which resulted in the creation of literacy centers in the target communities through which some participants succeeded in learning to read and write in their languages. The following table presents the languages, years, centers, and the corresponding number of learners as follows:

Table 4: List of literacy centers created and the Number of learners

\begin{tabular}{|l|l|l|l|}
\hline Language & Years & Centres & No of learners \\
\hline \multirow{4}{*}{ Bafut } & 2008 & 36 & 775 \\
\cline { 2 - 4 } & 2009 & 31 & 347 \\
\cline { 2 - 4 } & 2010 & 34 & 421 \\
\hline \multirow{4}{*}{ Kom } & 2008 & 29 & 339 \\
\cline { 2 - 4 } & 2009 & 32 & 480 \\
\cline { 2 - 4 } & 2010 & 34 & 499 \\
\hline
\end{tabular}




\begin{tabular}{|l|l|l|l|}
\hline \multirow{4}{*}{ Kako } & 2008 & 17 & 120 \\
\cline { 2 - 4 } & 2009 & 13 & 27 \\
\cline { 2 - 4 } & 2010 & 15 & 86 \\
\hline \multirow{3}{*}{ Ngiemboon } & 2008 & 37 & 4879 \\
\cline { 2 - 4 } & 2009 & 28 & 3560 \\
\cline { 2 - 4 } & 2010 & 22 & 2478 \\
\hline
\end{tabular}

Table 4 shows the total number of literacy centers and the total number of learners for the target languages from 2008 to 2010. A comparative analysis of the total number of learners for the selected languages indicates that Ngiemboon had the highest number of learners and the best literacy development followed in the second and third positions by Bafut and Kom while Kako had the least number of centers and learners. This is an indication that there was relatively more response to literacy in Ngiemboon than in the other communities. This also implies that audio Scripture use in Ngiemboon stimulated more interest in literacy among the participants than those of Bafut, Kom, and Kako.

\subsection{The Development of Personal Reading through Proclaimers}

The usefulness of Proclaimers was also evident in the development of personal reading skills by most of the participants. Since most Christians who had the NT translated Bibles did not read them because of illiteracy, these audio devices were definitely useful as a springboard to their personal reading. However, the sustainability of the newly acquired skill for some of the participants will depend on the continuous use of these tools, especially if they do not break down. In fact, the acquisition of reading skills particularly to those who were illiterates, is inestimable because this category of speakers can more likely embark on the revitalization of their languages Tasah (2012). If a growing number illiterate population keep developing an interest in reading, illiteracy will be greatly reduced and many will be loyal and involved in different aspects of their language development.

Apart from the data analyzed on the creation of literacy centres and the number of listeners, statistics were also obtained from the Proclaimer and literacy coordinators on the literacy skills of some participants who had learned either to read or relatively to write since the start of the programme. The table below presents the number of speakers who have acquired reading and writing skills in the course of the programme.

Table 5: Distribution of respondents according to the ability to read and write

\begin{tabular}{|l|l|l|l|l|l|l|l|l|}
\hline \multirow{2}{*}{$\begin{array}{l}\text { Language/ } \\
\text { Skills }\end{array}$} & Bafut & \multicolumn{2}{l}{ Kom } & \multicolumn{2}{l|}{ Kako } & Ngiemboon \\
\cline { 2 - 9 } & Reading & Writing & Reading & Writing & Reading & Writing & Reading & Writing \\
\hline & 901 & 718 & 1234 & 358 & 205 & 104 & 3153 & 986 \\
\hline Total & 1619 & 1592 & & 305 & 4139 \\
\hline
\end{tabular}

Table 5 shows that speakers in the different communities under study have been responding differently to literacy activities right from the inception of the literacy program. The Ngiemboon community as usual was the most responsive to literacy, with the highest number of those who could read and write or both. The analysis indicates that out of 4139 participants who claimed to be literate through the programme in Ngiemboon, 3153 could read while only a 986 could write. Bafut comes second with a total number of 1619 out of which the majority 901 could read while only 718 claimed to write. Kom occupies the third position with a response rate of 1592 participants, out of which 1234 could read while 358 could write. The least response in terms of literacy was Kako, with only 305 participants out of whom 205 could read while 104 could write. If the total number of participants who could read and write from these communities since the inception of the programme in 2008 keeps growing, then the progressive reduction of illiteracy in these communities is irreversible.

Moreover, it is important to point out that the participants did not only learn to read the translated NT thanks to the use of Proclaimers which facilitated the reading task for some of them. They also learned to read other literacy materials in their respective languages. Their use was invaluable because they enabled participants to have access to their Scriptures among a wide range of other available materials in their communities. Therefore, it was necessary to find out if the respondents actually read some of the materials already produced in their languages to establish the extent to which the device can be used in literacy promotion. The table below presents the different materials that the respondents were reading. 
Table 6: Distribution of respondents according to the Materials Read

\begin{tabular}{|l|l|l|l|l|}
\hline $\begin{array}{l}\text { Language / } \\
\text { Reading material }\end{array}$ & Bafut & Kom & Kako & Ngiemboon \\
\hline Primer 1 & $42(56.7 \%)$ & $30(39.9 \%)$ & $20(26.2 \%)$ & $33(41.77 \%)$ \\
\hline Primer 2 & $42(56.7 \%)$ & $9(11.97 \%)$ & $24(31.92 \%)$ & $22(27.85 \%)$ \\
\hline Transition books & $20(27 \%)$ & $14(18.62 \%)$ & $40(53.2 \%)$ & $43(54.43 \%)$ \\
\hline Lexicon & $9(12.15 \%)$ & $5(6.65 \%)$ & $32(42.56 \%)$ & $11(13.92 \%)$ \\
\hline Bible portions & $41(55.35 \%)$ & $18(23.94 \%)$ & $44(58.52 \%)$ & $43(54.43 \%)$ \\
\hline VNT Bible & $65(87.75 \%)$ & $24(31.92 \%)$ & $37(49.21 \%)$ & $46(58.23 \%)$ \\
\hline Shell books & $12(16.2 \%)$ & $6(7.98 \%)$ & $40(53.2 \%)$ & $17(21.52 \%)$ \\
\hline Local newspaper & $15(20.25 \%)$ & $17(22.61 \%)$ & $40(53.2 \%)$ & $28(35.44 \%)$ \\
\hline Others & $2(2.7 \%)$ & $11(14.63 \%)$ & $9(11.97 \%)$ & $14(17.72 \%)$ \\
\hline None of the above & $3(4.05 \%)$ & $5(6.65 \%)$ & $4(5.32 \%)$ & - \\
\hline
\end{tabular}

The above table demonstrates that in Bafut, 42(56.7\%) of the respondents read Primer 1, 42(56.7\%) read Primer 2, 20(27\%) read transition books, 9(12.15) read the lexicon, 41(55.35\%) read VNT Bible portions, 65(87.75\%) read the VNT Bible, 12(16.2\%) read shell books, $15(20.25 \%)$ read the local newspaper, $2(2.7 \%)$ read others and $3(4.05 \%)$ do not read any of the afore-mentioned materials.

The analysis of materials read in the Kom language reveals that 30(39.9) read primer1, 9(11.97\%) read primer 2, 14(18.62\%) read transition books, 5(6.65 read the lexicon, 18(23.94\%) read VNT Bible portions, while 24(31.92\%) read the VNT Bible, 6(7.98\%) read shell books, $17(22.161 \%)$ read the local newspaper, $11(14.63 \%)$ read others and $5(6.65 \%)$ read none of the above. With regards to Kako, the statistics showed that 20(26.6\%) read Primer 1, 24(31.92\%) read primer 2, 40(53.2\%) read transition books, $32(42.56 \%)$ read the lexicon, 44(58.52\%) read VNT Bible portions, 37(49.21\%) read the VNT Bible, 40(53.2\%) read shell books, $40(53.2 \%)$ read the local newspaper while 9 (11.97\%) read others and 4 (5.32\%) read none of the afore-mentioned materials.

In terms of the Ngiemboon language, the exploitation of reading materials according to the analysis indicates that 33(41.77\%) of the respondents read Primer 1, 22(27.85\%) read Primer 2, 43(54.43\%) read transition books, 11(13.92\%) read the lexicon, 43(54.43\%) read VNT Bible portions, 46(58.23\%) read the VNT Bible, 17(21.52\%) read shell books, 28(35.44\%) read the local newspaper, $14(17.72 \%)$ read some other materials.

Generally, the above analyses provide prima facie evidence that apart from the VNT Bible and Bible portions where the majority of the respondents claimed to read in the four communities, they also read other available materials in the respective languages. The importance of literacy was also felt in many churches in the target communities where the numbers of readers increased especially in Ngiemboon and Bafut. As indicated in the introduction, the programme also resulted in the enhancement of the revitalization of the languages under study. This is based on participant observation, interviews and some testimonies (see Appendix 1).

\subsubsection{Language Revitalization through literacy}

According to Paulston, Chen, and Connerty (1993:273), language revitalization is imparting new vigour to a language still in limited use, most commonly by increased use through the expansion of domains. For a language to increase its use in any domain, it needs to be planted like a seed, watered and weeded before it fructifies. The fact that all concepts in the religious domain have been flexibly translated before recording them in the audio format clearly demonstrates that other domains of these languages are translatable. However, the availability of audio Scriptures in the target languages, among other materials, vastly enhance their status and prestige. In this connection, Proclaimer is a perfect demonstration of language revitalization in the religious domain.

\subsubsection{Language Prestige and Vitality}

The translation and recording of the NT into Audio Scriptures in the selected languages has enhanced their prestige and vitality and thereby raised them on a parity relatively with English and French in the domain of religion with languages already written not only in the context of Cameroon and further afield, but also in Africa or the world at large. The enhanced status of these languages through this apparatus gives the speakers a sense of identity and the negative perception that some if not most speakers had about their languages is slowly diminishing with the increased use of the Proclaimers. 


\subsubsection{Positive Perception and Value of local languages}

Information elicited from promoters reveals that an increasing number of community members positively perceive the value of the local languages since the beginning of the programme. The speakers' positive perception of local languages can be due to the fact that many of them did not know that their languages have been developed to the point where they are already used in the audio format. As one listener surprisingly exclaimed, "I am overwhelmed with joy. I didn't know the extent to which our language has been developed. I will learn it". Thus, the realization that the languages under study have been reasonably developed, particularly in the religious domain, is one of the motivating factors for some of the speakers to be committed to literacy activities and revitalization of their languages.

\subsubsection{Change of attitudes}

Although speakers' attitudes towards their languages before and in the course of the literacy activities were not expressly assessed, it is safe to note on the basis of participant observation that the use of this apparatus has been greatly changing the speakers' perception of their languages since most of them seem to have understood, accepted and appreciated the usefulness of Audio Scriptures. This assessment was based on the growing enthusiasm and interest manifested by most of the speakers as well as the diverse testimonies recorded from some of the participants (see Appendix 1). This new wave of commitment to the Proclaimer and literacy activities are positive signs that unfavourable attitudes towards local languages, even by the minority of the speakers, are progressively changing. In addition, continuous church-based and adult literacy classes in the target languages are also changing and shaping the mentalities of most speakers particularly those involved in the activities and giving them a heightened sense of value about their languages. In fact, it is giving wider community awareness about the possibility for the revitalization of their languages so that even skeptics may also be involved in their community literacy activities. Therefore, the revitalization of these languages is irreversible since many participants increasingly seem to see more value and importance in their languages through literacy activities.

\subsubsection{Audio Scriptures : a spiritual ground for language revitalization}

The use of these devices has provided a fertile ground for the speakers to be nourished with the Scriptures orally and their desire to be involved in the promotion of their language through literacy activities. This is crucial because it favors language maintenance and revitalization.

\subsubsection{Audio Scripture:a cultural ground language revitalization}

Audio Scriptures can also be considered an instrument is fanning the nearly extinguished fire of speakers' natural love for their languages and culture. As such, it is a voice that is helping community members particularly the youths uncover their love for their local languages and this is useful and necessary for language revitalization. It is important to note that the more they are used, the greater community members will value and valorize their languages and culture and the more likely they will be involved in their language's revitalization. The increasing use of this device may also open up avenues for the eventual revitalization of the selected languages among others.

\subsubsection{Acceptance}

Generally, speakers' felt-needs are a powerful motivator for accepting anything geared towards improving their language. Linguistically, the real impact of the Scriptures from this apparatus was not in the gospel message alone, but in the way attention was given to correct use of words, natural phrasing, and appropriate expression in the translation of the VNT Bible such that these qualities, together with a change of volume, pace, and pitch combine to reveal the true feeling and value of the language embedded in the Scriptures. Thus, some participants' acceptance was due to the stabilizing effect of the Audio Scriptures on their language use as some testified (see Appendix1) their increased exposure to wide vocabulary and rich, diverse expressions in the Proclaimer greatly helped in enriching and stabilizing their languages.

\subsubsection{Literacy in oral Communities}

Orality is a culturally appropriate and effective method of communicating within an oral culture. The running of Audio Scriptures in oral communities is important in that they reduce resistance to Christianity and literacy in the selected languages by enabling them to approach the Scriptures with a deeper understating and application into different life situations. Scripture used in audio format also enables participants, some of whom were illiterate, to memorize biblical verses, while some immediately enrol in literacy classes because of their perception and appreciation of their languages. This allows them to have an experience with literacy, and thus increases their chances of supporting and revitalizing their languages. This implies that the ramifications of the use of the Proclaimers have gone far beyond the religious perspective to areas such as literacy, language revitalization and, above all, the effective intergenerational transmission of the language through Audio Scriptures. 


\section{Perspectives on the use of Proclaimers in the development of literacy and language Revitalization}

Translating and, if possible, recording all relevant, up-to-date information in various fields available in foreign languages into these languages, among others, should be every community's unchanging vision. Developing new relevant, up-to-date teaching and reference materials, including online and electronic instructional materials would greatly widen the domains in which these languages are used. For instance, this can be done by developing these languages actively and quickly in areas of science and technology.

Similarly, developing more community-based functional literacy programs that will improve the lives of the indigenous natives would certainly have a rippling effect on literacy development and language revitalization. In this connection, an increased number of linguists need to be trained in all areas of language development and translate some materials on income generation activities and lifesaving materials that are useful for the improvement of each community's living standards.

In addition, language communities and relevant NGOs working on language-related issues need to increase their capacity to carry out sustainable language-based development for the benefit of these communities while churches and some members of the elite of the target languages need to support the programme financially by supporting all language development-based projects in their communities in order to generate more interest and for community involvement in the revitalization of their languages.

The growing interest in listening groups in the different communities could enhance the effective acquisition of the language by some of those who do not sufficiently know their MT and also provide a platform for intergenerational transmission of these languages. The continuous use of this apparatus could project these languages as 'models' in terms of ongoing modernization and vitality. This growing interest should attract more researchers and linguists in particular to carry out research on the programme and this may result ultimately in the increased vitality of the target languages.

In addition, the permanent and continuous use of this programme will enhance and revitalize their literacy activities if they put a permanent literacy infrastructure for all related literacy issues. The growing participation of the population in literacy classes and life-long learning will likely facilitate and enhance their language revitalization. The training and production of vital materials in different domains that constitute a concrete demonstration of each community's willingness or readiness to revitalize their language is a permanent challenge.

The instigation of literacy programmes with new interests, habits, and attitudes have emerged. The mobilization of resources for the support and sustenance of the programme needs to be part and parcel of every community's goal while the formation of more church-based and literacy centers is fundamentally vital for the sustainability of the programme. The enthusiasm and interest in the programme need to keep growing for the increased maintenance and revitalization of the target languages.

From the analysis and testimonies gathered, the Proclaimers can be considered as devices for literacy that have shaped the perception and appreciation of the participants and motivated most of them to have growing esteem and a sense of pride in their MT. The use of the gadgets have widened respondents' awareness about the value and prestige of their languages and stimulated their interest in literacy.

\section{Conclusion}

This paper has looked at the Proclaimer as an emerging medium for literacy promotion and language revitalization in four selected communities in Cameroon. On the basis of the results obtained from the communities under study, the Proclaimers can be established as tools capable of ensuring large scale literacy development and language revitalization. Their use in the target languages has been considered as one of the most effective turning points in the fight against illiteracy and language endangerment. They are a useful response to illiteracy and can be considered catalysts that greatly enhance the status and vitality of endangered languages. This is because entrenched attitudes have been shaped since the introduction of these devices in the selected communities. The immediate consequence is an increasing community response to literacy activities, which occupy a special place in any community's language revitalization. Since a growing number of participants from the four communities have been increasingly appreciating and accepting the value of their languages based on data analyzed and some testimonies thanks to the availability and use of these gadgets, promoters, linguists, elites, churches and advocates of language revitalization, amongst others, can exploit the situation for increasing community mobilization on literacy development and language revitalization. If Proclaimers seem to be gaining ground and are necessary for other parts of the world, they are even more relevant in Africa, particularly in rural areas that are still largely illiterate, because their use enhances literacy development. This is why Crystal (2000:19) opines that "people must be able to read and write if they or their language is to have a future in an increasingly computer-literate civilization". 


\section{References}

[1] Bediako, k. (1995). Christianity in Africa: the renewal of a non-western religion. Edinburg: Edinburg University Press.

[2] Brown R.D. (2000). "Audiovisual Scriptures: An Emerging medium for promotion and presentation". In Notes on Scriptures in use and language programs. No 206-89. SIL Dallas Texas. Crystal, D. 2000. Language Death. Cambridge: Cambridge University Press.

[3] Crystal, D. (2000). Language Death. Cambridge: Cambridge University Press.

[4] Maluleke, T.S. (2004). "African Christianity, the Bible and Theology". Pages 161-176 in Bible Translation and African Audiences. G.Yoke and P.M. Renju (Eds). Nairobi: Acton Publishers, 2004.

[5] Margetts, R. (2019). "Which Audio Player? Listening to the translated Scriptures: a review of today's digital audio players. Fourth Edition.

[6] Paulston, C. B., P.C. Chen, and M.C. Connerty (1993). "Language regenesis: A conceptual overview of language revival, revitalization and reversal) In Journal of Multilingual and Multicultural Development 14, 4: 275-286

[7] Sanneh, L. (1989). Translating the message: the missionary impact on culture. Maryknoll: Orbis Books.

[8] Sogoard, V. (2000). Media in Church and Mission. Communicating the Gospel. Pasadena, California. U.S.A

[9] Tadadjeu, M. (2004). Language, Literacy and Education in African Development: A perspective from Cameroon. SIL International.

[10] Tasah, N. J. (2012). "The Impact of Literacy in the Revitalization of Less Endangered Languages: a Case Study of Bafut, Kom, Kako, and Ngiemboon" Unpublished PhD Thesis, University of Yaounde1.

[11] Wycliffe (2009). Partners in Bible Translation, www.wycliffe.org (Accessed on 12 July 2021)

\section{Appendix 1: Some common Testimonies gleaned from some participants in the Four Communities}

"The programme has helped me to be able to express my deepest feelings something which a foreign language cannot do" "I have learned to value my language and culture more and more in the course of the programme"

"Before the programme started in our community, I used to despise or feel inferior to use my MT in the presence of nonnative speakers. It has encouraged me to realize that my language is important as God speaks through it in the Scriptures"

"I have realized the value that our language has and I am determined to learn it formally so that I can also read fluently like those whose voices were used in recording the translated Scriptures"

"In the course of the programme, I changed my attitude towards our language since God speaks through it in the Scriptures" "I used to think that my language was limited only to community use but its use in audio Scriptures has increased my knowledge in our language and I can teach it to my children"

"The section of parables in the Proclaimer has increased my love for Scripture because they contain great lessons and I will learn my language in order to read them often"

- $\quad$ "Before the programme started, I did not really know who I was and the importance of my language. In the course of the programme, my attitude toward my language and culture changed positively and I know who I am in God's plan"

"The programme has caused me to desire to read my VNT Bible in my MT instead of the French version"

- " "I have realized that my MT is so important for Scriptural comprehension and that our culture is also important"

"I have learned through the programme that Christianity can be lived in my culture; which is something I did not know"

"It has helped me to know that our culture is important although some pastors or priests who may not understand it well enough condemn some if not certain aspects as sinful"

"I did not know how to communicate effectively to God through my language and now I can communicate with the right vocabulary while praying"

"I have realized that I need to use my MT to communicate the Scriptures to others and also use them in my family devotions"

"I have observed tremendous increase in church attendance and literacy participation since the programme started in our community"

"I have learned to value my language and culture and I am involved in literacy classes"

- $\quad$ "Even though I could not read in my language when the programme started, the growing interest in the programme made me to buy a VNT in my MT and today I can read effectively"

"The programme is so important to me because it has helped me to understand the VNT Scriptures deeper and better than before"

"The lesson that has struck me most is the fact that our culture is in God's plan and now I know that God does not neglect or despise any culture"

"In the course of listening, I identify more with my language and culture than before"

"The programme has changed my ways of life deeply since the Scriptures penetrate deeply into our lives"

"I have learned much of my language through the Scriptures and scarcely insert foreign words in my speech except words the equivalents of which I do not know in my MT" 